\title{
Acceso a los servicios de energía. Una crítica a la Agenda 2030 de México
}

\section{Access to Energy Services. A Critique of Mexico's 2030 Agenda}

\author{
Rigoberto García Ochoa* (D) http://orcid.org/0000-0001-9379-3473 \\ Alvaro Bracamonte Sierra** (D) http://orcid.org/0000-0002-8523-0846
}

\section{Resumen}

El objetivo del artículo es identificar y describir a los hogares mexicanos en función del acceso a los servicios de energía y de sus características socioeconómicas principales, para mostrar la relación entre el acceso a la electricidad y a los servicios que brinda la energía. Se aplicó una metodología cuantitativa con técnicas multivariantes, que incluyó el análisis de conglomerados de K medias y el de correspondencias. Los resultados advierten que hay hogares con alta homogeneidad $y$ heterogeneidad intergrupal, escenario que revela un problema de desigualdad social en torno al acceso a los servicios de energía, esto a pesar de que casi todos cuentan con electricidad. La limitante del estudio fue la falta de información oficial sobre la capacidad (potencia), tamaño y marca de los equipos electrodomésticos. Se concluye que el Estado debe implementar una política energética que reconozca esta diferenciación social, con un enfoque trasversal de sostenibilidad económica, social y ambiental.

Palabras clave: servicios de energía; Agenda 2030; análisis de conglomerados K media; análisis de correspondencias; desarrollo sostenible; política energética.

\begin{abstract}
This article aims at identifying and describing Mexican households in terms of access to energy services and their main socioeconomic characteristics in order to show the relationship between access to electricity and to the services that energy provides. A quantitative methodology with multivariate techniques was applied, which included the K-means cluster analysis and the correspondence analysis. The results warn that there are households with high homogeneity and intergroup heterogeneity, a scenario that reveals a problem of social inequality regarding access to energy services, despite the fact that almost all of them have electricity. The limitation of the study was the lack of official information on the capacity (power), size and brand of home appliances. It follows that the State must implement an energy policy that recognizes this social differentiation, with a cross-sectional approach of economic, social and environmental sustainability.

Keywords: energy services; 2030 Agenda; K-means cluster analysis; correspondence analysis; sustainable development; energy policy.
\end{abstract}

Cómo citar: García Ochoa, R., y Bracamonte Sierra, A. (2019). Acceso a los servicios de energía. Una crítica a la Agenda 2030 de México. región y sociedad, 3 I, el I46. doi: I0.22I 98/rys20I9/3I/II46

* Autor para correspondencia. El Colegio de la Frontera Norte. Departamento de Estudios Urbanos y del Medio Ambiente. Calle Reforma No. 528, colonia del Rosario, C. P. 84020, Nogales, Sonora, México. Correo electrónico: rigo@colef.mx

** El Colegio de Sonora, Programa de Estudios Transfronterizos. Avenida Obregón 54, colonia Centro, C. P. 83000, Hermosillo, Sonora, México. Correo electrónico: abraca@colson.edu.mx

Recibido: 5 de noviembre de 2018

Aceptado: 8 de febrero de 2019

Liberado: 21 de agosto de 2019

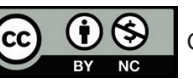

Esta obra está protegida bajo una Licencia

Creative Commons Atribución-No Comercial 4.0 Internacional. 


\section{Introducción}

México se comprometió a cumplir la Agenda 2030 para el Desarrollo Sostenible, un plan de acción mundial impulsado por Naciones Unidas, tendiente a mejorar la calidad de vida y reducir la pobreza de las personas, donde se plantean 17 Objetivos de Desarrollo Sostenible (ODS) que cubren las dimensiones económica, social y ambiental (Naciones Unidas [NU], 2018). El objetivo 7 propone: "Garantizar el acceso a una energía asequible, segura, sostenible y moderna para todos", cuya meta 7.1 establece: "De aquí a 2030, garantizar el acceso universal a servicios energéticos asequibles, fiables y modernos". Este escenario valida implícitamente el rol que desempeña la energía como vía para reducir la pobreza y la armonía con el medio ambiente.

La medición del acceso universal a los servicios energéticos será de acuerdo con la proporción de la población con acceso a la electricidad. ${ }^{1} \mathrm{Al}$ respecto, se advierte una ambigüedad conceptual en torno a la noción de servicio de energía, ${ }^{2}$ situación que puede derivar en la implementación de políticas energéticas y el establecimiento de metas que no mejoren el desarrollo humano y sostenible de la población, esencia de todos los ODS. Esta confusión representa un problema de investigación cuya naturaleza se compone de los aspectos siguientes:

1. Si el cumplimiento de la meta se mide exclusivamente con el acceso a la electricidad (indicador 7.1.1), deja de lado otros combustibles que satisfacen necesidades humanas. De acuerdo con la Secretaría de Energía (SENER, 2017), el consumo energético total del sector residencial mexicano se distribuye así: leña (33.1\%); gas licuado (32.7); electricidad (28.1); gas seco (4.9) y energía solar (0.8). Como se advierte, la meta no considera el acceso a gas licuado y al natural que, en conjunto, representan $37.7 \%$ del consumo energético total, tampoco el uso de leña que es tan importante en México, ya que una tercera parte del consumo energético residencial corresponde a este combustible. Es decir, la meta 7.1 del ODS 7 no establece criterio alguno para que en los hogares mexicanos el gas y la leña se usen de manera sustentable y contribuyan al bienestar humano.

2. Aunque existen varias definiciones de servicio de energía, se aprecia una visión limitada del concepto. La mayoría señala que los servicios de energía (iluminación, cocción de alimentos, calentamiento de agua, calefacción y ventilación) son esenciales para el desarrollo humano, ya que proporcionan beneficios sociales y apoyan la generación de ingresos y empleos

1 En la Estrategia nacional para la puesta en marcha de la Agenda 2030 (Gobierno Federal, 2016), el Estado mexicano se comprometió a alcanzar dos objetivos adicionales: a) "De aquí a 2030, aumentar considerablemente la proporción de energía renovable en el conjunto de fuentes energéticas" (meta 7.2), medido a partir de la proporción de la energía renovable en el consumo final total de energía (indicador 7.2.1) y b) "Duplicar la tasa mundial de mejora de la eficiencia energética" (meta 7.3), cuya métrica sería la intensidad energética, medida en función de la energía primaria y el producto interno bruto (indicador 7.3.1).

2 Ambigüedad compartida por Naciones Unidas ya que, si bien en la meta 7.1 establece el término servicio de energía, deja a consideración de cada país la elección del indicador empleado para medir el cumplimiento de cada meta. 
(Kozulj, 2009; Modi, McDade, Lallement y Saghir, 2005; Sovacool, 2011). Sin embargo, la meta 7.1 del ODS 7 equipara el acceso exclusivo a la electricidad con el de los servicios que brinda la energía. No obstante, que una vivienda tenga acceso a la electricidad o a cualquier otro combustible no significa que cuente con otros servicios de energía; por ejemplo, es posible que esté conectada a la red eléctrica local y carezca de iluminación adecuada, de un sistema de ventilación apropiada, es decir, de una que brinde confort térmico. Esta ventilación la pueden proporcionar aparatos de aire acondicionado, ventiladores, ventanas o bien la sombra de árboles, o también otros servicios que ofrece la energía.

3. Al entrar en vigor la Agenda 2030 (1 de enero de 2016), cerca de $99 \%$ de los hogares mexicanos ya contaban con acceso a la electricidad (Instituto Nacional de Estadística y Geografía [INEGI], 2017). Es decir, la meta estaba prácticamente cumplida con anticipación. Ello revela una visión parcial del Estado sobre el papel que desempeña la energía como vehículo para alcanzar un desarrollo sustentable, ya que no propuso metas e indicadores que respondieran a la realidad económica y social actual del país, en función de los servicios de energía.

Con base en esta problemática, resulta pertinente especificar el acceso real de la población de México a los servicios de energía -entendidos en su acepción más amplia e integral posible-. Aquí, la hipótesis es que los hogares mexicanos se clasifican en grupos con alta homogeneidad interna y heterogeneidad externa en función del nivel de acceso a los diferentes servicios de energía, situación que muestra la falta de correspondencia entre acceso a la electricidad y a los servicios de energía. Con base en este planteamiento, el objetivo es identificar y describir a dichos grupos de población a fin de contar con un panorama preciso de las condiciones que guardan los hogares en lo que se refiere al acceso a electricidad y a los servicios de energía. El reconocimiento de esa asimetría (homogeneidad y heterogeneidad grupal) abre una vía para conocer la realidad empírica del tema investigado. Tener claridad en torno a la relación entre energía y desarrollo humano en México permitirá cumplir el compromiso signado por el gobierno en el marco de la Agenda 2030 para el Desarrollo Sostenible (meta 7.1 del ODS 7).

En la primera parte del artículo se explica la forma en que surgió el término servicio de energía como tema prioritario para alcanzar los Objetivos de Desarrollo del Milenio (ODM), y cómo la Agenda 2030 de Naciones Unidas incorporó el número 7. Esto se aborda mediante una revisión de la literatura especializada y la identificación de los ejes de análisis. Enseguida se describen los conceptos principales empleados en esta investigación y la fuente de información, para después explicar una propuesta para diferenciar los niveles de satisfacción de los servicios de energía en los hogares, así como las herramientas: el análisis de conglomerados $\mathrm{K}$ medias y el de correspondencias. En la sección de resultados aparece una descripción de la tipología de hogares encontrada en función del acceso a servicios de energía, así como la caracterización socioeconómica de los grupos de hogares. Con base en los resultados obtenidos, se hacen propuestas 
para reducir la desigualdad en el acceso a servicios de energía, y fortalecer así la dimensión social de la política energética en los hogares. El artículo finaliza con las conclusiones y los comentarios finales.

Servicios de energía y desarrollo humano sostenible

El papel de los servicios de energía limpia y asequible en el desarrollo humano ha cobrado relevancia científica y política. Con ese telón de fondo, la Asamblea General de las Naciones Unidas aprobó, en septiembre del año 2000, la Declaración del Milenio, alianza mundial cuyo propósito principal consistió en reducir los niveles extremos de pobreza en el mundo y, para alcanzarlo estableció los ODM, que consideraban metas medibles y plazos de ejecución para 2015 (UN, 2009).

Aunque el tema de energía no aparecía en ellos de manera explícita, se empezó a reconocer que el acceso a servicios de energía limpia y asequible era una condición necesaria para lograr todos los objetivos. El asunto se tornó urgente al comprobarse que en el mundo había 2400 millones de personas que utilizaban biomasa como combustible (leña o carbón) para cocinar y preparar alimentos, 1600 millones no contaban con energía eléctrica en sus viviendas y, además, las proyecciones indicaban que para 2030 otros 1400 registrarían una situación similar (Modi et al. 2005, pp. 1-2). Esta perspectiva ominosa se reconoció en el Plan de Implementación de la Cumbre Mundial para el Desarrollo Sostenible de Johannesburgo, en 2002, una de cuyas conclusiones principales fue que "todos los países deberían tomar acciones conjuntas para proporcionar servicios de energía seguros, limpios y accesibles", a fin de facilitar el logro de los ODM (UN, 2002, p. 5).

En esa coyuntura, el término servicio de energía cobró notoriedad en investigaciones en torno a la relación entre servicios de energía y desarrollo humano y sostenible. Destaca en este punto el trabajo de Modi et al., en el cual se define a los servicios de energía como "los beneficios que producen los portadores de energía para el bienestar humano” (2005, p. 9). Ejemplos de estos beneficios son la cocción de alimentos o el confort térmico dentro de la vivienda, que se produce con el calor generado por la quema de algún combustible (portador), o la iluminación, con energía lumínica generada con electricidad. Una de las conclusiones es que el acceso a servicios de energía limpia y asequible es una condición indispensable para alcanzar la mayoría de los ODM.

Por otra parte, Sovacool (2011) aportó conocimiento importante en torno a las desigualdades sociales relacionadas con los servicios de energía, con una definición similar a la de Modi et al. (2005) y la caracterización de servicios de energía de Resiter y Devine (1981); también señaló que éstos se refieren a lo que los usuarios quieren cuando los usan: cocinar alimentos, iluminar de manera adecuada las habitaciones de una vivienda o usar una computadora con internet sin interrupciones eléctricas. Los resultados de dicho estudio muestran que el aprovechamiento de los servicios de energía varía en función del nivel socioeconómico de las familias, las áreas urbanas o rurales y el consumo energético. 
Por ejemplo, los hogares de bajos ingresos emplean una amplia diversidad de combustibles de baja calidad, por lo general estiércol, leña, gas licuado de petróleo y carbón, pero menor variedad de servicios. Los de ingresos medios usan electricidad y gas natural; en menor medida carbón, gas licuado de petróleo y queroseno; no obstante, utilizan la energía para disfrutar de más servicios. Por último, los hogares de altos ingresos usan los mismos energéticos o combustibles que los anteriores, con la diferencia de que consumen mucha más energía y tienen más equipos y enseres electrodomésticos de lujo. ${ }^{3}$

Sovacool concluye que las intervenciones de política pública deben reorientarse hacia los servicios de energía y no a los combustibles y tecnologías de energía. Por ejemplo, una que busque asegurar un consumo mínimo necesario de electricidad para alcanzar una temperatura adecuada dentro de las viviendas limitaría otras opciones que podrían aprovecharse, si esta política se encaminara a mejorar el confort térmico. Una opción sería mejorar el aislamiento térmico o implementar un diseño bioclimático que reduzca la demanda energética. En el caso de la iluminación se plantea que si una política pública se enfocara solo a la eficiencia energética de las lámparas, se dejarían de lado otras alternativas que podrían asegurar la misma iluminación, incluso con menos consumo energético, como instalar ventanas y cristales en los techos para aprovechar al máximo la luz del sol o pintar las paredes con colores claros.

Según Cravioto, Yamasue, Okumura e Ishihara (2014), en México las ciencias sociales deberían abordar el tema de los servicios de energía en función del consumo energético y del uso de tecnologías requeridas para el bienestar humano en un contexto cultural. Es decir, la relación que tienen las personas con su entorno (determinada por creencias, valores, costumbres y tradiciones) se manifiesta de maneras diferentes en los usos finales de energía. En esta línea, Cravioto y Yamasue (2017) y Cravioto et al. (2014) aplicaron el enfoque de Sovacool (2011) en localidades ubicadas en la zona metropolitana del valle de México, y encontraron que el uso mixto de combustibles no crecía en función del ingreso de los hogares. Estos resultados advierten sobre la importancia de considerar, además del ingreso, variables de índole social que reflejen las condiciones culturales de la población.

Fell (2017) advierte sobre una polisemia en torno al término servicio de energía, ya que después de realizar un análisis de contenido de 185 artículos de investigación que tocan el tema, encontró 27 definiciones y 173 tipos diferentes de servicios de energía. El motivo principal de esta polisemia es que los conceptos servicio y uso final de energía se usan de forma indistinta, problema teórico y conceptual que debe superarse para mejorar la comunicación y evitar la confusión, tanto en el campo científico como en el político. Fell sugiere esta definición: "Los servicios de energía son aquellas funciones realizadas con energía que facilitan los medios para obtener los servicios o estados finales deseados" (2017, p. 137). De acuerdo con ella, los servicios de energía propor-

3 Por ejemplo, usan un equipo central de aire acondicionado o varios individuales en la mayoría de las habitaciones de la vivienda; refrigeradores o lavadoras de ropa modernas y de gran capacidad; más focos, principalmente para la iluminación nocturna de exteriores y equipos de videojuegos, entre otros. 
cionan beneficios a las personas (por ejemplo la climatización de las viviendas que brinda confort térmico, o el calor para la cocción de alimentos) por medio de un trabajo o función útil, a través de los usos finales (consumo energético de los equipos o enseres electrodomésticos). De manera similar a Sovacool (2011), Fell destaca que los servicios de energía más importantes en el contexto del hogar son los de iluminación, cocción de alimentos, calefacción de espacios, calentamiento de agua y refrigeración.

Hasta aquí, la revisión de la literatura expuesta confirma la relevancia de los servicios de energía para el desarrollo sostenible. Al terminar el periodo de aplicación de los ODM, Naciones Unidas implementó la Agenda 2030 de Desarrollo Sostenible con 17 objetivos que cubren las dimensiones económica, social y ambiental. A diferencia de los ODM, en esta ocasión sí se reconoció el papel que desempeñan los servicios de energía para mejorar la calidad de vida de la población mundial, esto a través de la meta 7.1 del ODS 7. En el caso de México, sin embargo, se observa una ambigüedad conceptual en los términos acceso a la electricidad y acceso a servicios de energía, situación que puede generar un abordaje inadecuado por parte del Estado para mejorar el desarrollo sostenible de la población.

\section{Metodología}

Para alcanzar el objetivo planteado aquí, se propone la estrategia metodológica siguiente: a) definir y clasificar los servicios de energía y sus usos finales; b) seleccionar la fuente de información; c) establecer niveles de satisfacción de los servicios de energía, y d) elegir el método.

\section{Definición y clasificación de servicios de energía}

La definición de servicio de energía de Modi et al. (2005) se adaptó con base en la revisión de la literatura especializada ya que, además de ser la más utilizada en el mundo, tiene la virtud de marcar una diferenciación clara entre servicio y uso final de energía en el hogar. Con esa premisa, aquí se adoptó esta definición: los servicios de energía son aquellos beneficios que produce el uso de energía para el bienestar humano en los hogares; es importante señalar que se eliminó el término portador de energía de la original, y se sustituyó por el de energía, debido a que este último es más intuitivo y fácil de comprender y empleado ampliamente en los ámbitos científico y académico.

La clasificación de los servicios de energía se basa en Sovacool (2011) y Fell (2017), resumida en la tabla 1, y contempla los siguientes: a) iluminación; b) entretenimiento; c) calentamiento de agua; d) refrigeración; e) cocción de alimentos; f) preparación de alimentos; h) limpieza de la vivienda (electrodomésticos), e i) confort térmico; cada uno está vinculado con sus usos finales respectivos, así como con el de uno o más energéticos o com- 
Tabla 1. Clasificación de servicios de energía, usos finales y tipo de energético utilizado

\begin{tabular}{|c|c|c|c|c|}
\hline $\begin{array}{l}\text { Servicio de } \\
\text { energía }\end{array}$ & $\begin{array}{l}\text { Contribución } \\
\text { al bienestar } \\
\text { social y desarrollo } \\
\text { humano }\end{array}$ & $\begin{array}{l}\text { Usos finales } \\
\text { de energía }\end{array}$ & Energético & $\begin{array}{c}\text { Porcentaje de } \\
\text { consumo total } \\
\text { sector residencial } \\
\text { (Agencia } \\
\text { Internacional } \\
\text { de Energía [AIE] } \\
\text { y SENER, 2011) }\end{array}$ \\
\hline Iluminación & $\begin{array}{c}\text { Contar con iluminación } \\
\text { adecuada en la vivienda } \\
\text { es un requisito necesario } \\
\text { para llevar a cabo las } \\
\text { actividades cotidianas, } \\
\text { cuando no hay } \\
\text { iluminación natural. } \\
\text { La privación de este servi- } \\
\text { cio incrementa la posibili- } \\
\text { dad de trastornos visuales } \\
\text { y cefalalgias, así como } \\
\text { problemas } \\
\text { ergonómicos, que } \\
\text { pueden causar accidentes } \\
\text { (Evans, 2001; Küller, Ballal, } \\
\text { Laike, Mikellides y Tonello, } \\
\text { 2006; Tonello, 2008; Wall } \\
\text { y Crosbie, 2009) }\end{array}$ & $\begin{array}{l}\text { Lámparas } \\
\text { incandescentes }\end{array}$ & Electricidad & 6.7 \\
\hline Entretenimiento & $\begin{array}{c}\text { Las actividades de ocio } \\
\text { y esparcimiento a través } \\
\text { de la televisión y la red } \\
\text { de internet contribuyen a } \\
\text { tener mejor calidad } \\
\text { de vida, ya que mejora } \\
\text { la comunicación familiar } \\
\text { y se facilita el acceso } \\
\text { a información, cultura } \\
\text { y conocimiento }\end{array}$ & $\begin{array}{l}\text { Computadora } \\
\text { de escritorio } \\
\text { o portátil }\end{array}$ & Electricidad & 3.0 \\
\hline \multirow[b]{2}{*}{$\begin{array}{c}\text { Calentamiento de } \\
\text { agua }\end{array}$} & \multirow{2}{*}{$\begin{array}{l}\text { Es necesario para muchas } \\
\text { actividades de limpieza } \\
\text { e higiene en el hogar, } \\
\text { como la ducha, la } \\
\text { limpieza y desinfección } \\
\text { de alimentos y utensilios. } \\
\text { El consumo energético } \\
\text { asociado con este servicio } \\
\text { representa } 48 \% \text { del total } \\
\text { en el sector residencial } \\
\text { mexicano } \\
\text { (AIE y SENER, 2011) }\end{array}$} & $\begin{array}{c}\text { Calentador } \\
\text { de agua }\end{array}$ & \multirow[b]{2}{*}{$\begin{array}{c}\text { Gas natural, } \\
\text { gas licuado, } \\
\text { electricidad, } \\
\text { energía solar, } \\
\text { leña }\end{array}$} & \multirow[b]{2}{*}{48.0} \\
\hline & & Estufa & & \\
\hline
\end{tabular}




\begin{tabular}{|c|c|c|c|c|}
\hline $\begin{array}{l}\text { Refrigeración } \\
\text { de alimentos }\end{array}$ & $\begin{array}{c}\text { Necesario para la } \\
\text { conservación de los } \\
\text { alimentos. Ayuda a } \\
\text { optimizar el tiempo } \\
\text { dedicado a la preparación } \\
\text { y cocción de alimentos. } \\
\text { Reduce o incluso elimina } \\
\text { la trasmisión de } \\
\text { enfermedades diarreicas } \\
\text { e infecciones intestinales } \\
\text { (Checkley et al., 2000; } \\
\text { Daniels et al.,2000; } \\
\text { Tangkanakul, } \\
\text { Tharmaphornpilas, } \\
\text { Datapon y } \\
\text { Sutantayawalee, 2000) }\end{array}$ & Refrigerador & Electricidad & 9.9 \\
\hline \multirow[b]{3}{*}{$\begin{array}{l}\text { Cocción de } \\
\text { alimentos }\end{array}$} & \multirow[b]{3}{*}{$\begin{array}{c}\text { Necesario para cocinar } \\
\text { los alimentos, satisfactor } \\
\text { indispensable para la } \\
\text { supervivencia humana. } \\
\text { El tipo de combustible } \\
\text { usado para cocinar tiene } \\
\text { implicaciones directas en } \\
\text { la salud de las personas. } \\
\text { En áreas rurales de países } \\
\text { pobres o en vías de } \\
\text { desarrollo, la exposición } \\
\text { al humo generado } \\
\text { con la quema de estos } \\
\text { combustibles perjudica } \\
\text { principalmente a mujeres } \\
\text { en edad fértil y menores } \\
\text { de edad, que produce } \\
\text { mortinatos y bajo peso al } \\
\text { nacer (World Health } \\
\text { Organization-World } \\
\text { Meteorological } \\
\text { Organization } \\
\text { [WHO-WMO], 2012) }\end{array}$} & Estufa de gas & \multirow[b]{3}{*}{$\begin{array}{c}\text { Gas licuado, } \\
\text { gas natural, } \\
\text { electricidad, } \\
\text { leña }\end{array}$} & \multirow[b]{3}{*}{27.5} \\
\hline & & Estufa de leña & & \\
\hline & & Estufa eléctrica & & \\
\hline \multirow{3}{*}{$\begin{array}{l}\text { Preparación } \\
\text { de alimentos }\end{array}$} & \multirow{3}{*}{$\begin{array}{c}\text { Necesario para preparar } \\
\text { alimentos. Los usos finales } \\
\text { de energía vinculados } \\
\text { con este servicio ayudan } \\
\text { a optimizar el tiempo } \\
\text { dedicado a la preparación } \\
\text { de alimentos }\end{array}$} & $\begin{array}{l}\text { Horno de } \\
\text { microondas }\end{array}$ & \multirow{3}{*}{ Electricidad } & \multirow{3}{*}{1.3} \\
\hline & & Tostador de pan & & \\
\hline & & Licuadora & & \\
\hline \multirow{3}{*}{$\begin{array}{c}\text { Limpieza } \\
\text { en el hogar } \\
\text { (electrodomésticos) }\end{array}$} & \multirow{3}{*}{$\begin{array}{c}\text { Necesario para la limpieza } \\
\text { en la vivienda, que } \\
\text { contribuye al bienestar } \\
\text { físico de las personas }\end{array}$} & Lavadora & \multirow{3}{*}{ Electricidad } & \multirow{3}{*}{1.0} \\
\hline & & Aspiradora & & \\
\hline & & Plancha & & \\
\hline \multirow[b]{3}{*}{$\begin{array}{l}\text { Confort } \\
\text { térmico }\end{array}$} & \multirow{3}{*}{$\begin{array}{c}\text { Este servicio se refiere a } \\
\text { un sistema de ventilación } \\
\text { o aire acondicionado } \\
\text { en la vivienda; } \\
\text { indispensable para } \\
\text { reducir la vulnerabilidad } \\
\text { de la población ante } \\
\text { climas extremos } \\
\text { (McMichael et al., 2003; } \\
\text { WHO-WMO, 2012) }\end{array}$} & Ventilador & \multirow[b]{3}{*}{ Electricidad } & \multirow[b]{3}{*}{2.5} \\
\hline & & $\begin{array}{c}\text { Aire lavado } \\
\text { (cooler) }\end{array}$ & & \\
\hline & & $\begin{array}{c}\text { Aire } \\
\text { acondicionado }\end{array}$ & & \\
\hline
\end{tabular}

Fuente: elaboración propia. 
bustibles. Con base en la distinción que hace Fell (2017) entre los conceptos de servicio y uso final de energía, se entiende que el segundo es el consumo energético de los equipos o enseres electrodomésticos que, al usarlos, contribuyen a brindar los servicios de energía a la población.

Fuente de información

La Encuesta Nacional de Ingreso y Gasto de los Hogares (ENIGH) de 2016 (INEGI, 2017) se seleccionó por ser la fuente de datos más reciente y exhaustiva sobre equipos, enseres electrodomésticos, características de las viviendas y condiciones socioeconómicas de las personas y los hogares. Si bien en México no se cuenta todavía con información de los usos finales de energía en los hogares, tampoco sobre la potencia y consumo energético de los equipos y enseres electrodomésticos, la ENIGH 2016 sí ofrece datos sobre la tenencia o propiedad de estos equipos y el año de su adquisición, y con ellos es posible conocer si cumplen con la normatividad oficial mexicana en materia de eficiencia energética (véase tabla 2). Con base en el objetivo general de este trabajo, se analizaron los hogares que en México tienen acceso a electricidad, que conforman $99 \%$ del total.

Tabla 2. Características de la ENIGH 2016

\begin{tabular}{|c|c|}
\hline Característica & Descripción \\
\hline Población objetivo & $\begin{array}{c}\text { Hogares de nacionales o extranjeros, que residen } \\
\text { habitualmente en viviendas particulares dentro } \\
\text { del territorio nacional }\end{array}$ \\
\hline Cobertura temporal & 2016 \\
\hline Cobertura geográfica & Nacional y estatal \\
\hline Tamaño de la muestra & 68511 viviendas \\
\hline Unidad de observación & El hogar \\
\hline Unidad de muestreo & La vivienda \\
\hline Unidad de análisis & El hogar, la vivienda y los integrantes del hogar \\
\hline Tipo de muestreo & $\begin{array}{c}\text { Probabilístico, a su vez el diseño es estratificado, } \\
\text { bietápico y por conglomerados, donde la unidad última } \\
\text { de selección es la vivienda y la unidad de observación } \\
\text { es el hogar; en consecuencia, los resultados se } \\
\text { generalizan a toda la población }\end{array}$ \\
\hline $\begin{array}{c}\text { Periodo de levantamiento } \\
\text { de la encuesta }\end{array}$ & Del 21 de agosto al 28 de noviembre de 2016 \\
\hline
\end{tabular}

Fuente: INEGI (2017). 


\section{Tabla 3. Niveles de satisfacción de los servicios de energía en los hogares de México}

\begin{tabular}{|c|c|c|}
\hline $\begin{array}{l}\text { Servicio de } \\
\text { energía }\end{array}$ & $\begin{array}{c}\text { Nivel de } \\
\text { satisfacción }\end{array}$ & $\begin{array}{l}\text { Descripción del nivel } \\
\text { de satisfacción }\end{array}$ \\
\hline \multirow{3}{*}{ Iluminación } & $\begin{array}{c}1 \text { (muy bajo } \\
\text { o bajo) }\end{array}$ & $\begin{array}{l}\text { Hasta un foco por habitación o al menos } 60 \% \\
\text { de lámparas fluorescentes ahorradoras }\end{array}$ \\
\hline & 3 (medio) & $\begin{array}{l}\text { Al menos un foco por habitación y } 61 \text { a } 90 \% \\
\text { de lámparas fluorescentes ahorradoras }\end{array}$ \\
\hline & 4 (alto) & $\begin{array}{l}\text { Al menos un foco por habitación y más de } 90 \% \\
\text { de lámparas fluorescentes }\end{array}$ \\
\hline \multirow{4}{*}{ Entretenimiento } & 1 (muy bajo) & No cuenta con televisor o computadora con acceso a internet \\
\hline & 2 (bajo) & Cuenta con televisor, pero no con computadora ni acceso a internet \\
\hline & 3 (medio) & Cuenta con televisor y computadora, pero no tiene acceso a internet \\
\hline & 4 (alto) & Cuenta con televisor o computadora con acceso a internet \\
\hline \multirow{3}{*}{$\begin{array}{l}\text { Calentamiento } \\
\text { de agua }\end{array}$} & $\begin{array}{c}1 \text { (muy bajo } \\
\text { o bajo) }\end{array}$ & $\begin{array}{c}\text { No dispone de calentador de agua o estufa, } \\
\text { o bien de estufa de gas o eléctrica }\end{array}$ \\
\hline & 3 (medio) & $\begin{array}{l}\text { No dispone de calentador de agua, pero sí de estufa } \\
\text { de leña sin chimenea }\end{array}$ \\
\hline & 4 (alto) & Dispone de calentador de gas, eléctrico o solar \\
\hline \multirow{4}{*}{$\begin{array}{l}\text { Refrigeración } \\
\text { de alimentos }\end{array}$} & 1 (muy bajo) & No cuenta con refrigerador \\
\hline & 2 (bajo) & $\begin{array}{l}\text { Cuenta con refrigerador que incumple la Norma Oficial Mexicana } \\
\text { de eficiencia energética (modelo } 1998 \text { o anterior) }\end{array}$ \\
\hline & 3 (medio) & $\begin{array}{l}\text { Cuenta con refrigerador que cumple con la NOM-015-ENER-1997 } \\
\text { (modelo } 1999 \text { a 2006) }\end{array}$ \\
\hline & 4 (alto) & $\begin{array}{l}\text { Cuenta con refrigerador que cumple con la NOM-015-ENER-2012 } \\
\text { (modelo } 2007 \text { a 2016) }\end{array}$ \\
\hline \multirow{2}{*}{$\begin{array}{l}\text { Cocción de } \\
\text { alimentos }\end{array}$} & $\begin{array}{c}1 \text { (muy bajo } \\
\text { o bajo) }\end{array}$ & $\begin{array}{l}\text { No tiene estufa, y cocina con un combustible diferente } \\
\text { al gas natural, gas licuado, leña o electricidad; } \\
\text { o tiene estufa de leña sin chimenea y cocina con leña }\end{array}$ \\
\hline & $\begin{array}{c}4 \text { (medio o } \\
\text { alto) }\end{array}$ & $\begin{array}{c}\text { Tiene estufa de gas o eléctrica y cocina con gas natural, gas licuado o } \\
\text { electricidad; o tiene estufa de leña con chimenea y cocina con leña }\end{array}$ \\
\hline \multirow{2}{*}{$\begin{array}{l}\text { Preparación } \\
\text { de alimentos } \\
\text { (cocina) }\end{array}$} & $\begin{array}{c}1 \text { (muy bajo } \\
\text { o bajo) }\end{array}$ & $\begin{array}{l}\text { No cuenta con alguno de estos equipos: horno de microondas, } \\
\text { licuadora, tostador de pan, o solo tiene uno }\end{array}$ \\
\hline & $\begin{array}{l}4 \text { (medio } \\
\text { o alto) }\end{array}$ & $\begin{array}{l}\text { Cuenta con dos o tres de estos equipos: horno de microondas, } \\
\text { licuadora, tostador de pan }\end{array}$ \\
\hline \multirow{4}{*}{$\begin{array}{l}\text { Higiene y } \\
\text { limpieza }\end{array}$} & 1 (muy bajo) & No cuenta con lavadora, plancha ni aspiradora \\
\hline & 2 (bajo) & Cuenta con uno de estos equipos: lavadora, plancha, aspiradora \\
\hline & 3 (medio) & Cuenta con dos de estos equipos: lavadora, plancha, aspiradora \\
\hline & 4 (alto) & Cuenta con lavadora, plancha y aspiradora \\
\hline \multirow{4}{*}{$\begin{array}{l}\text { Confort térmico } \\
\text { (sistema de } \\
\text { ventilación } \\
\text { y/o aire } \\
\text { acondicionado) } \\
\text { Aplica } \\
\text { exclusivamente } \\
\text { en hogares } \\
\text { localizados en } \\
\text { regiones con } \\
\text { climas cálidos }\end{array}$} & 1 (muy bajo) & No cuenta con equipo de ventilación o aire acondicionado \\
\hline & 2 (bajo) & $\begin{array}{l}\text { Los ventiladores son insuficientes (menos de uno por dos habitantes } \\
\text { de la vivienda) }\end{array}$ \\
\hline & 3 (medio) & $\begin{array}{l}\text { Cuenta con ventiladores suficientes (al menos uno por cada dos ha- } \\
\text { bitantes de la vivienda), no tiene equipo de ventilación o aire acondi- } \\
\text { cionado }\end{array}$ \\
\hline & 4 (alto) & $\begin{array}{c}\text { Cuenta con ventiladores suficientes (al menos uno por cada dos } \\
\text { habitantes de la vivienda), o bien con sistema de ventilación o aire } \\
\text { acondicionado }\end{array}$ \\
\hline
\end{tabular}


Niveles de satisfacción de los servicios de energía

En todos los casos se establecieron cuatro niveles de satisfacción o aprovechamiento de los servicios de energía; desde el valor más bajo (1) hasta el más alto (4). Sin embargo, el análisis descriptivo de esta clasificación arrojó valores muy pequeños en algunas categorías, evidencia de que había casos desviados (outliers) que podían incidir en su análisis posterior. Ante esta situación, dichos niveles se reclasificaron de acuerdo con Hair, Anderson, Tatham y Black (2007), y quedaron como se resume en la tabla 3. Esta división se tomó de Practical Action (2016), que analiza los niveles de acceso a energía a escala global, y se adaptó al entorno nacional. Es importante destacar que en México no hay información oficial sobre la capacidad (potencia), tamaño y marca de los equipos y enseres electrodomésticos. Solventar esta limitante metodológica implicó adaptar la información disponible, ya que su ausencia impide una mayor precisión sobre los niveles de satisfacción de los servicios de energía considerados. ${ }^{4} \mathrm{El}$ procedimiento aplicado ayuda a conocer de manera general el escenario actual del aprovechamiento y/o privación de los principales servicios de energía en los hogares de México. Es un primer paso que deberá perfeccionarse en el futuro, en consonancia con la disponibilidad de información sobre los servicios y usos finales de energía en el sector residencial. ${ }^{5}$

\section{Método}

Para clasificar a los hogares en función del acceso o satisfacción de los servicios de energía, se utilizó la técnica de investigación análisis de conglomerados $\mathrm{K}$ medias, que agrupa los objetos o unidades de análisis (en este caso hogares) en conglomerados, con dos características principales: se maximiza la homogeneidad interna de cada uno y se maximiza la heterogeneidad entre ellos (Hair et al., 2007). Esto significa que los que integran un conglomerado son más similares entre sí que los objetos que conforman los otros, en función de un valor teórico, que en esta investigación son los niveles de acceso a los servicios de energía en los hogares.

Es preciso aclarar que el análisis de conglomerados $\mathrm{K}$ medias no identifica el número óptimo de conglomerados, por lo cual se debe asignar antes. Para ello y, como paso previo para identificarlo, se tomó una muestra de 3\% de la original, y se aplicó el método de análisis de conglomerados jerárquico. Este procedimien-

4 Por ejemplo, fue imposible estimar el nivel de iluminación en las habitaciones (sala, comedor, recámaras), ya que no se conoce la potencia y el tiempo de encendido de las lámparas. Ante esta situación, se optó por considerar como umbral de satisfacción que la vivienda cuente al menos con una lámpara en cada habitación, así como el porcentaje de las que son fluorescentes ahorradoras de todas las que hay en la vivienda.

5 Ya se cuenta con los resultados de una encuesta sobre los usos finales de energía en los hogares mexicanos, según informaron funcionarios del INEGI y de la Comisión Nacional para el Uso Eficiente de Energía en México. La información que arrojó dicha encuesta será de gran importancia para mejorar la propuesta de clasificación de los servicios de energía en México, así como para análisis futuros de usos de energía. 
to, que es el recomendado en la literatura especializada (Everitt y Dunn, 2001; Hair et al., 2007; Kaufman y Rousseeuw, 2009), se aplicó al caso de estudio y se encontró que el número óptimo es de 16 conglomerados.

Tabla 4. Indicadores económicos, sociales y espaciales considerados en el AC y ACM

\begin{tabular}{|c|c|c|c|}
\hline Variable & Categoría & $\begin{array}{l}\text { Acrónimo } \\
\text { categoría }\end{array}$ & Descripción categoría \\
\hline \multirow{10}{*}{$\begin{array}{l}\text { Decil de } \\
\text { ingreso } \\
\text { corriente } \\
\text { del hogar }\end{array}$} & 1 & DI1 & $\begin{array}{c}\text { Ingreso trimestral hasta } \$ 11769.00 \\
\text { (en pesos mexicanos) }\end{array}$ \\
\hline & 2 & $\mathrm{D} 12$ & Ingreso trimestral de $\$ 11770.05$ a 16903.60 \\
\hline & 3 & DI3 & Ingreso trimestral de $\$ 16905.83$ a 21470.37 \\
\hline & 4 & DI4 & Ingreso trimestral de $\$ 21471.35$ a 26444.07 \\
\hline & 5 & DI5 & Ingreso trimestral de $\$ 26444.45$ a 32060.48 \\
\hline & 6 & DI6 & Ingreso trimestral de $\$ 32060.56$ a 38752.20 \\
\hline & 7 & DI7 & Ingreso trimestral de $\$ 38753.39$ a 47595.86 \\
\hline & 8 & $\mathrm{D} 18$ & Ingreso trimestral de $\$ 47596.63$ a 61412.38 \\
\hline & 9 & D19 & Ingreso trimestral de $\$ 61420.10$ a 87872.25 \\
\hline & 10 & DI10 & Ingreso trimestral de $\$ 87890.05$ o más \\
\hline \multirow{4}{*}{$\begin{array}{l}\text { Tamaño de } \\
\text { localidad }\end{array}$} & 1 & RUR & Localidades rurales de hasta 2499 habitantes \\
\hline & 2 & $\mathrm{SR}$ & Localidades semirurales de 2500 a 14999 habitantes \\
\hline & 3 & $\mathrm{CP}$ & $\begin{array}{l}\text { Localidades urbanas pequeñas } \\
\text { de } 15000 \text { y } 99999 \text { habitantes }\end{array}$ \\
\hline & 4 & CG & Localidades urbanas mayores de 100000 habitantes \\
\hline \multirow{5}{*}{$\begin{array}{c}\text { Edad del } \\
\text { jefe del } \\
\text { hogar }\end{array}$} & 1 & EDAD 1 & 14 a 34 años \\
\hline & 2 & EDAD 2 & 35 a 47 años \\
\hline & 3 & EDAD 3 & 48 a 60 años \\
\hline & 4 & EDAD 4 & 61 a 73 años \\
\hline & 5 & EDAD 5 & 74 años o más \\
\hline \multirow{3}{*}{$\begin{array}{l}\text { Situación } \\
\text { conyugal }\end{array}$} & 1 & Con pareja & $\begin{array}{l}\text { El jefe de hogar vive con su pareja, } \\
\text { casado o en unión libre }\end{array}$ \\
\hline & 2 & Sin pareja & El jefe de hogar es viudo, separado o divorciado \\
\hline & 3 & Soltero & El jefe de hogar es soltero y sin pareja \\
\hline \multirow{4}{*}{$\begin{array}{c}\text { Educación } \\
\text { del jefe del } \\
\text { hogar }\end{array}$} & 1 & PRIM & Hasta primaria incompleta \\
\hline & 2 & SEC INC & Primaria completa o secundaria incompleta \\
\hline & 3 & PREP INC & Secundaria completa o preparatoria incompleta \\
\hline & 4 & PROF & Preparatoria completa, profesional o posgrado \\
\hline
\end{tabular}

Fuente: elaboración propia, con base en Druckman y Jackson (2008); Healy y Clinch (2004); O'neill y Chen (2002), con información del INEGI (2017). 
Después se aplicaron las técnicas análisis de correspondencias $(\mathrm{AC})^{6}$ y análisis de correspondencias múltiple (ACM); en la tabla 4 aparece la relación entre dichos conglomerados y una serie de variables socioeconómicas.

El AC y el ACM tienen la ventaja de ofrecer una representación gráfica de los mapas factoriales contenidos en planos bidimensionales o tridimensionales del patrón de relaciones existente entre las categorías de las variables y los casos (columnas y filas). El procedimiento inherente a esta técnica se compone de dos pasos principales, el primero es encontrar las dimensiones o factores con sus valores propios respectivos (eigenvalues), que se obtienen de manera jerárquica, de tal forma que la primera (eje de las abscisas o X) contiene la mayor parte de la inercia total, mientras que la segunda (eje de las ordenadas o $Y$ ) el resto de la inercia total. El segundo paso consiste en obtener los puntajes de cada objeto o caso (hogares), así como la cuantificación de las categorías de las variables analizadas. Estos puntajes indican la posición de cada hogar en uno de los cuatro cuadrantes del plano factorial obtenido, así como su relación con las categorías de las variables analizadas. Es preciso aclarar que el AC ofrece los resultados correspondientes a dos variables, mientras que el ACM lo hace con más de dos. En este trabajo, primero se mostrarán los resultados del AC entre los conglomerados de hogares y cada variable económica, social y espacial considerada (véase tabla 4); después los resultados del ACM, que resume el patrón de relaciones de las categorías correspondientes al conjunto de variables analizadas.

Por último, es importante destacar que, más que analizar el efecto que producen una o más variables independientes en una dependiente, tanto el AC como el ACM generan un plano factorial que muestra el patrón de relaciones entre las unidades de análisis u objetos (nube de puntos objeto) y las categorías o propiedades de las variables en estudio (nube de puntos modalidades). Este método se adapta así al objetivo del trabajo, ya que no se pretende analizar los determinantes de los niveles de satisfacción de los servicios de energía en los hogares, sino identificar el patrón de relaciones entre dichos niveles y las características socioeconómicas de ellos.

\section{Resultados}

Tipología de hogares en función del nivel de acceso a servicios de energía

Al aplicar el método de análisis de $\mathrm{K}$ medias, se agruparon los 16 conglomerados identificados siguiendo una secuencia en función del acceso a los servicios de energía (véase tabla 5): las celdas en color rojo indican niveles muy bajos, los intermedios están en amarillo y los altos en verde. ${ }^{7}$

6 El AC y el ACM son técnicas de análisis multivariante desarrolladas y perfeccionadas por Jean Paul Benzécri, la cuales pertenecen a la llamada escuela francesa de datos (Baranger y Niño, 2009; Greenacre, 2017; Roux y Rouante, 2010).

7 Los resultados que se presentan en la tabla 5 corresponden a los centroides de los conglomerados finales obtenidos con el software SPSS 21. Un centroide cercano al valor de la categoría de un servicio de energía indica que el conglomerado correspondiente se caracteriza por presentar un nivel de acceso (categoría) similar a dicho servicio. Por ejemplo, el valor "3.77" obtenido por el conglomerado 16 en el servicio refrigeración de alimentos (R), indica que se caracteriza por un acceso alto (4). 


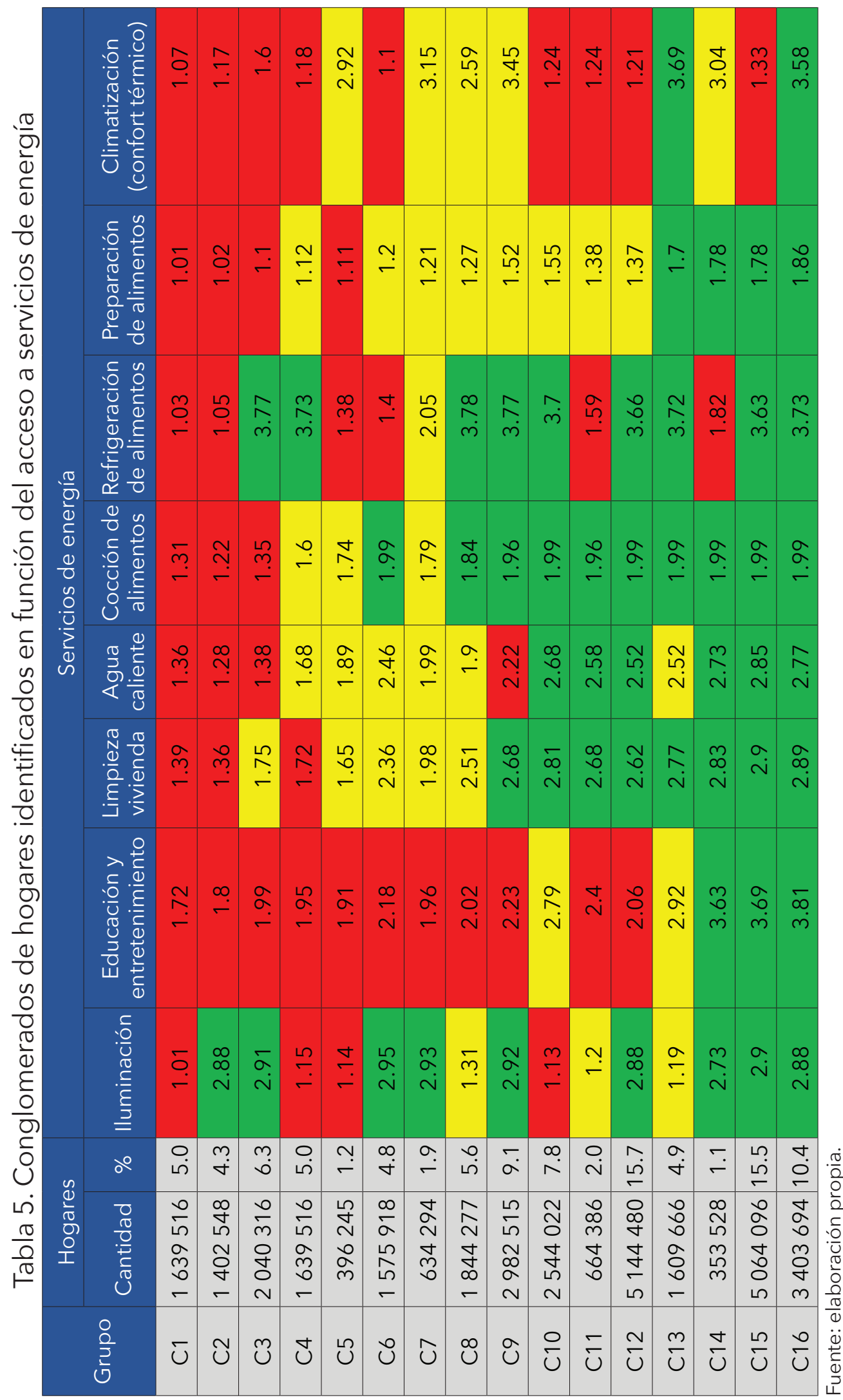


El conglomerado C1 presenta los niveles más bajos de acceso a todos los servicios de energía, seguido de los C2 y C3. Estos resultados evidencian que en 5082380 hogares, los cuales representan 15\% del total nacional, el acceso a la mayoría de los servicios de energía es muy bajo.

En los conglomerados C4 al C7 el acceso es bajo, aunque en condiciones ligeramente mejores a las del grupo anterior. En este caso se observa un acceso medio a los servicios de calentamiento de agua, cocción de alimentos, limpieza de la vivienda (excepto en el C4), y preparación de alimentos (salvo en el C5). En conjunto, estos cuatro conglomerados agrupan a 4245973 hogares, que representan alrededor de $13 \%$ del total nacional.

Después se aprecian los conglomerados C8 al C12, conformados por 13179 680 hogares, y representan poco más de $40 \%$ del total nacional; tienen acceso alto a los servicios de cocción de alimentos, limpieza de la vivienda (con excepción del C8), y refrigeración de alimentos (salvo el C11). Un rasgo distintivo de éstos es su acceso medio a la preparación de alimentos. Se descubrió una diferencia significativa con respecto a los conglomerados anteriores: tienen un acceso mejor a la mayoría de los servicios de energía, excepto al de preparación de alimentos y al de confort térmico.

Por último, hay 10430984 hogares (31.9\% del total) que conforman los conglomerados C13 al C16, cuya característica principal es su acceso más alto a los servicios de energía; el del C13 es el más alto a la mayoría de los servicios, con excepción de iluminación, entretenimiento y calentamiento de agua, en los cuales es medio, y el del C14 solo es bajo en el de refrigeración de alimentos y medio en confort térmico. De igual forma, el acceso del C15 es bajo solo al confort térmico, mientras que el $\mathrm{C} 16$ es el único que tiene acceso alto a todos los servicios de energía.

\section{Caracterización económica, social y espacial}

La primera variable por considerar es el decil de ingreso. En la figura 1 se muestra el plano factorial con la nube de puntos de las variables "conglomerados" (C1 al C16) y "decil de ingreso" (D1 a D10). Los resultados indican que la primera dimensión (eje de las abscisas) explica $79.6 \%$ de la inercia total, mientras que la segunda (eje de las ordenadas), 18.3\%, por tanto, entre ambas variables explican $98 \%$ de la inercia total (véase tabla 6). La primera dimensión discrimina los valores extremos de las dos variables, ya que los deciles más bajos de ingreso (D1 al D5), así como los conglomerados con acceso más bajo a servicios de energía ( $\mathrm{C} 1 \mathrm{al}$ C8) se encuentran a la izquierda del origen (cuadrantes II y III); mientras que las categorías restantes, que corresponde a los valores más altos, están a la derecha del origen (cuadrantes I y IV).

Estos resultados sustentan la crítica a la meta 7.1 del ODS 7, pues a pesar de que todos los hogares analizados cuentan con electricidad, muchos de ellos carecen de la mayor parte de los servicios de energía para satisfacer las necesidades humanas; la mayoría de los hogares que se encuentran en esta situación son aquéllos cuyos ingresos son más bajos, se localizan en el primer cuadrante de la figura 1. 
Figura 1. Plano factorial: patrón de relaciones entre conglomerados de hogares y decil de ingreso

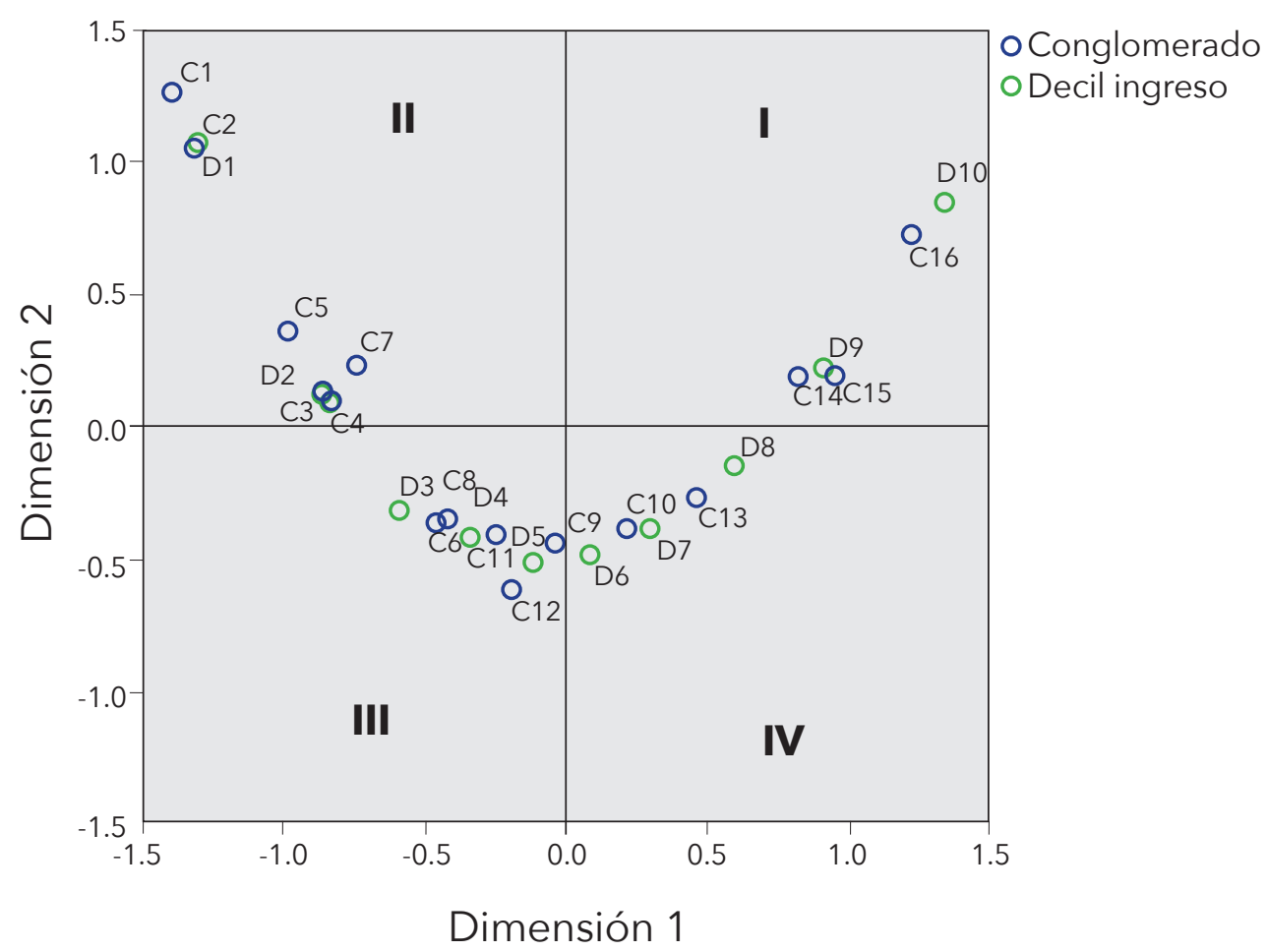

Fuente: elaboración propia.

Tabla 6. Resumen del modelo de las variables, conglomerados y decil de ingreso

\begin{tabular}{|c|c|c|c|}
\hline \multirow{2}{*}{ Dimensión } & \multicolumn{3}{|c|}{ Varianza } \\
\cline { 2 - 4 } & Valor singular & Inercia & Proporción de inercia (\%) \\
\hline 1 & 0.593 & 0.352 & 79.60 \\
\hline 2 & 0.285 & 0.081 & 18.30 \\
\hline \multicolumn{2}{|c|}{ Total } & 0.667 & 97.90 \\
\hline
\end{tabular}

Fuente: elaboración propia.

En la variable "tamaño de localidad", la primera dimensión discrimina a las localidades rurales, que están a la izquierda del origen, del resto ubicadas a la derecha del origen (véase figura 2). En este caso, la primera dimensión -eje de las abscisas- explica 95.1\% de la inercia total (véase tabla 7). En el segundo cuadrante hay una nube de puntos que corresponde a hogares rurales (RUR) con acceso muy bajo a los servicios de energía; después, en el cuarto cuadrante se observan los ubicados principalmente en localidades semirurales (SR) y ciudades pequeñas $(C P)$, con acceso medio. En el cuarto cuadrante están los hogares con 
Tabla 7. Resumen del modelo de las variables conglomerados y tamaño de localidad

\begin{tabular}{|c|c|c|c|}
\hline \multirow{2}{*}{ Dimensión } & \multicolumn{3}{|c|}{ Varianza } \\
\cline { 2 - 4 } & Valor singular & Inercia & Proporción de inercia (\%) \\
\hline 1 & 0.482 & 0.232 & 95.10 \\
\hline 2 & 0.101 & 0.01 & 4.20 \\
\hline & Total & 0.667 & 99.30 \\
\hline
\end{tabular}

Fuente: elaboración propia.

Figura 2. Plano factorial: patrón de relaciones entre conglomerados de hogares y tamaño de localidad

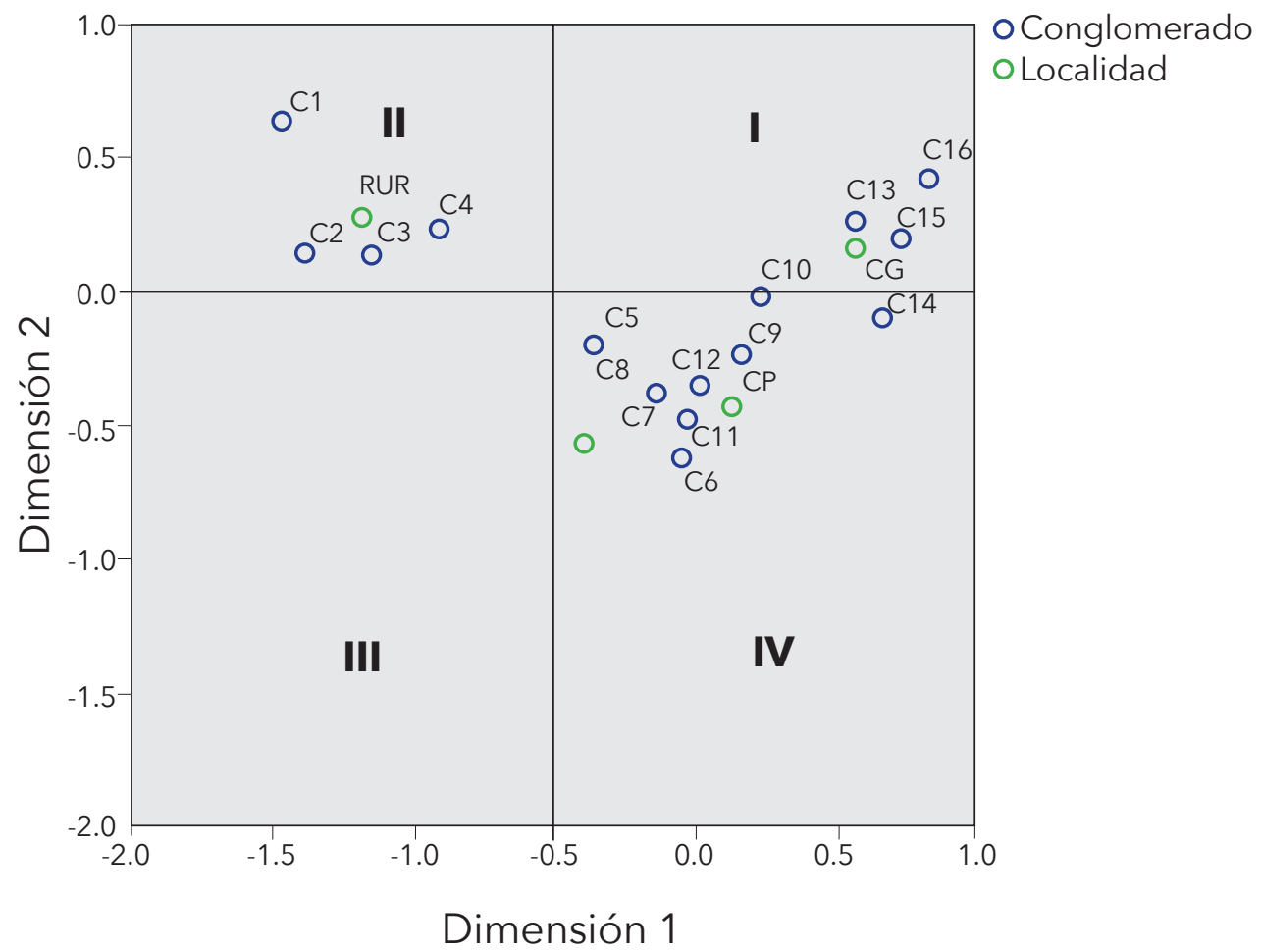

Fuente: elaboración propia. 
mejores condiciones de ingreso y acceso a servicios de energía. Estos resultados evidencian que la mayoría de los hogares rurales mexicanos sufren la privación de los servicios de energía, a pesar de contar con electricidad.

En la variable "edad del jefe del hogar" no se observa una relación clara con el nivel de acceso a servicios de energía (véase figura 3). Lo mismo sucede con la de "situación conyugal" (véase figura 4). Es evidente que en ambos casos no hay una tendencia clara en la nube de puntos que demuestre una relación consistente entre los dos conglomerados.

Figura 3. Plano factorial: patrón de relaciones entre conglomerados de hogares y edad del jefe del hogar

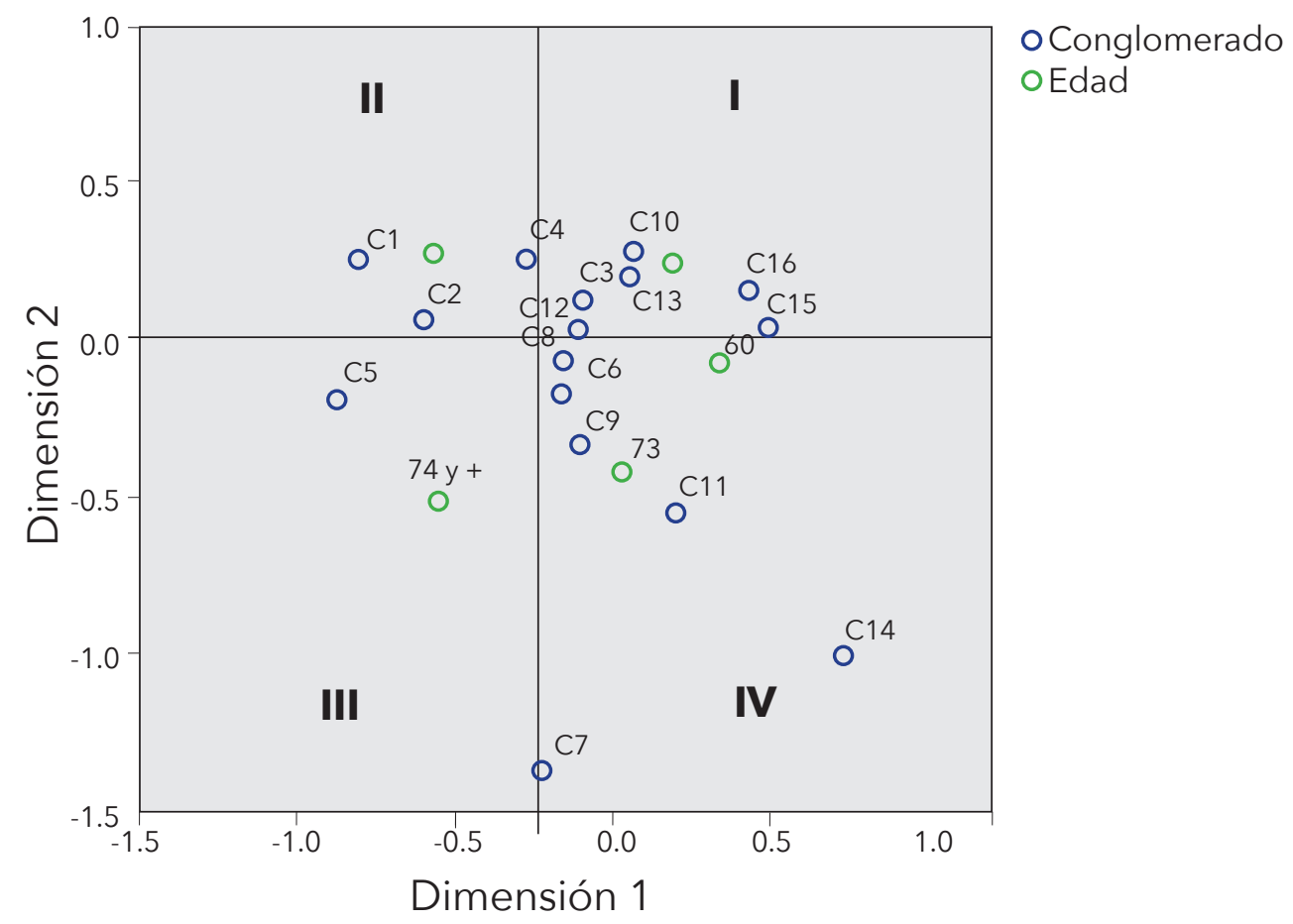

Fuente: elaboración propia.

En la figura 5 se muestra la relación entre los conglomerados de hogares y la variable "educación del jefe del hogar". Hay una tendencia clara, que empieza en el segundo cuadrante, donde es evidente la relación entre los hogares con acceso más bajo a servicios de energía y la primaria completa, como el grado máximo de educación; en el tercero y cuarto, hay una relación entre los niveles medios de acceso y la escolaridad de secundaria y preparatoria, y en el primero aparecen los valores más altos de ambas variables. La primera dimensión del plano factorial explica $92.0 \%$ de la inercia total, mientras que la segunda solo $7.8 \%$ (véase tabla 8 ). 
Figura 4. Plano factorial: patrón de relaciones entre conglomerados de hogares y situación conyugal del jefe del hogar

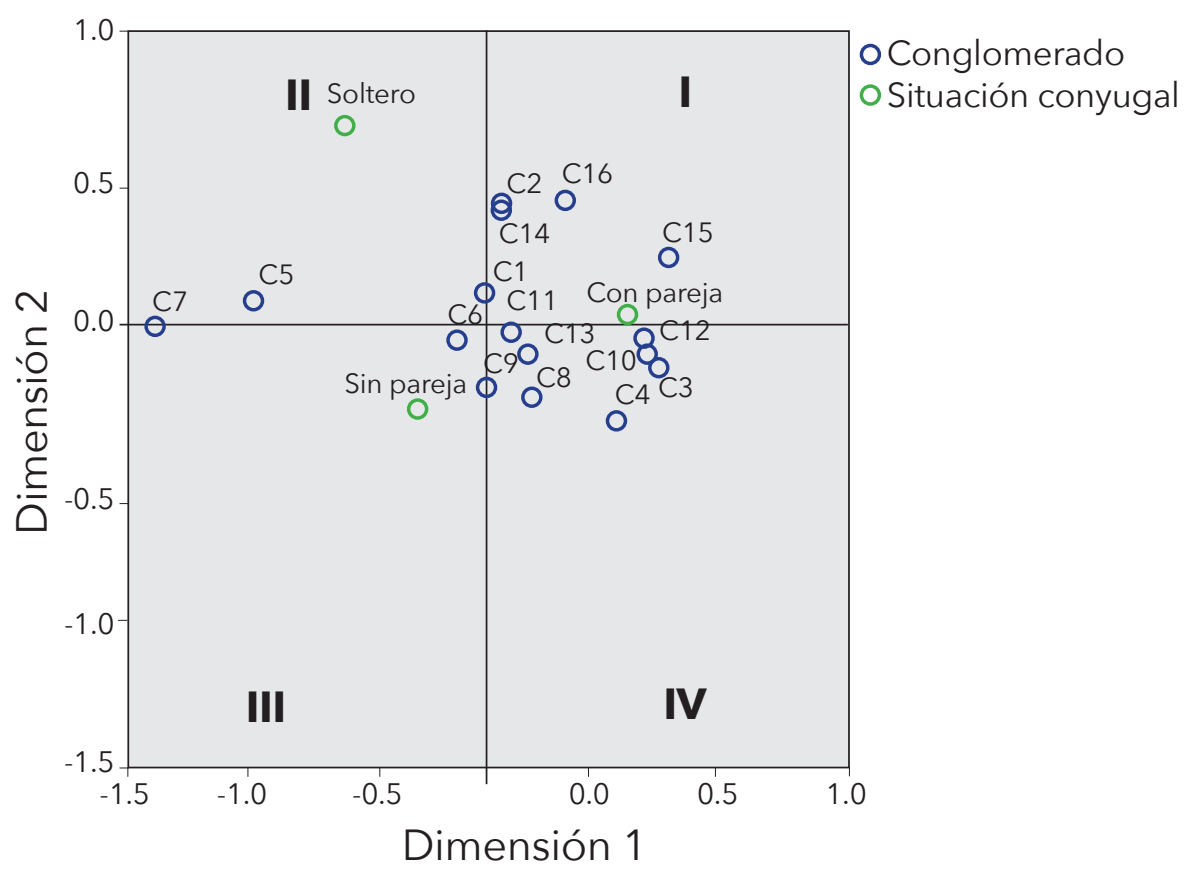

Fuente: elaboración propia.

Figura 5. Plano factorial: patrón de relaciones entre conglomerados de hogares y educación del jefe del hogar

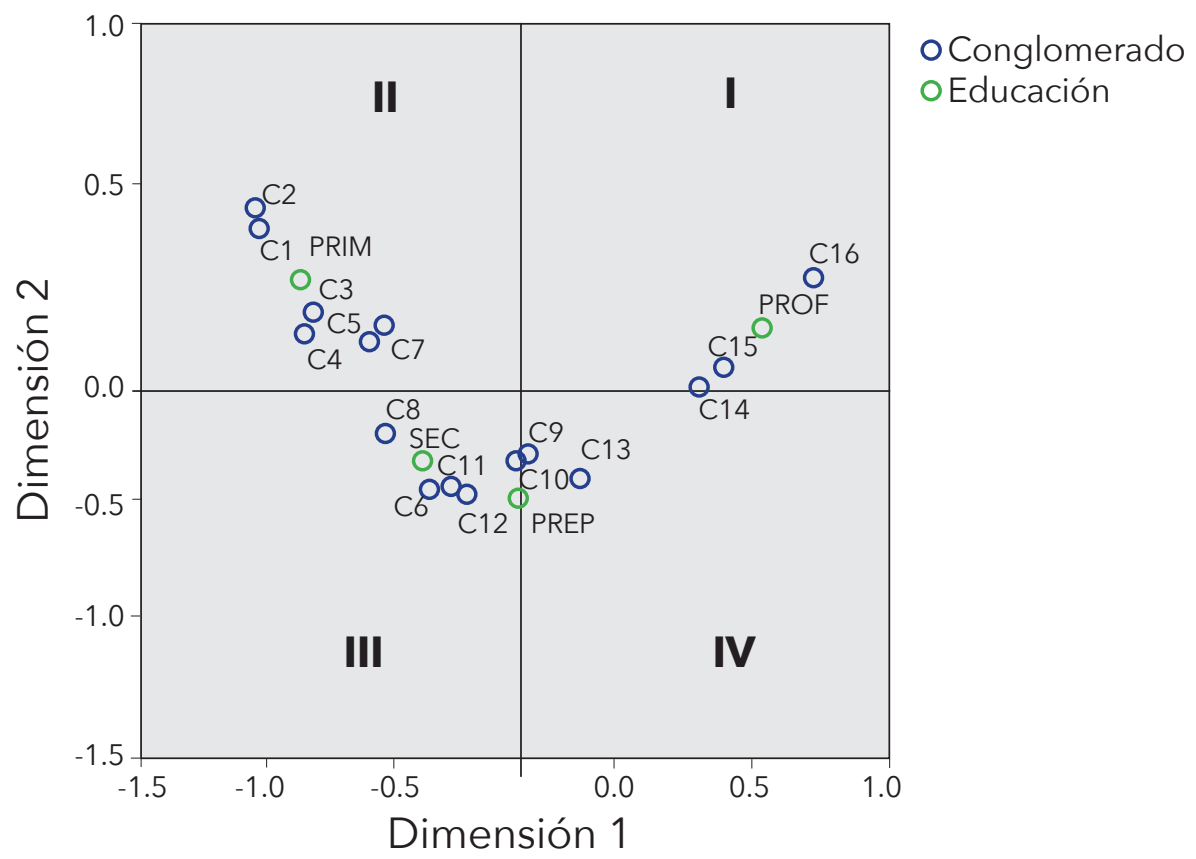

Fuente: elaboración propia. 
Tabla 8. Resumen del modelo de las variables conglomerados y educación del jefe del hogar

\begin{tabular}{|c|c|c|c|}
\hline \multirow{2}{*}{ Dimensión } & \multicolumn{3}{|c|}{ Varianza } \\
\cline { 2 - 4 } & Valor singular & Inercia & Proporción de inercia (\%) \\
\hline 1 & 0.471 & 0.222 & 92.00 \\
\hline 2 & 0.137 & 0.019 & 7.80 \\
\hline & Total & 0.667 & 99.80 \\
\hline
\end{tabular}

Fuente: elaboración propia.

En resumen, los resultados del análisis de correspondencia muestran un patrón significativo de relaciones de las variables "conglomerados de hogares" (acceso a servicios de energía), "decil de ingreso corriente del hogar", "tamaño de localidad” y "educación del jefe del hogar" (véase figura 6). La nube de

Figura 6. Plano factorial: patrón de relaciones del conjunto de variables analizadas

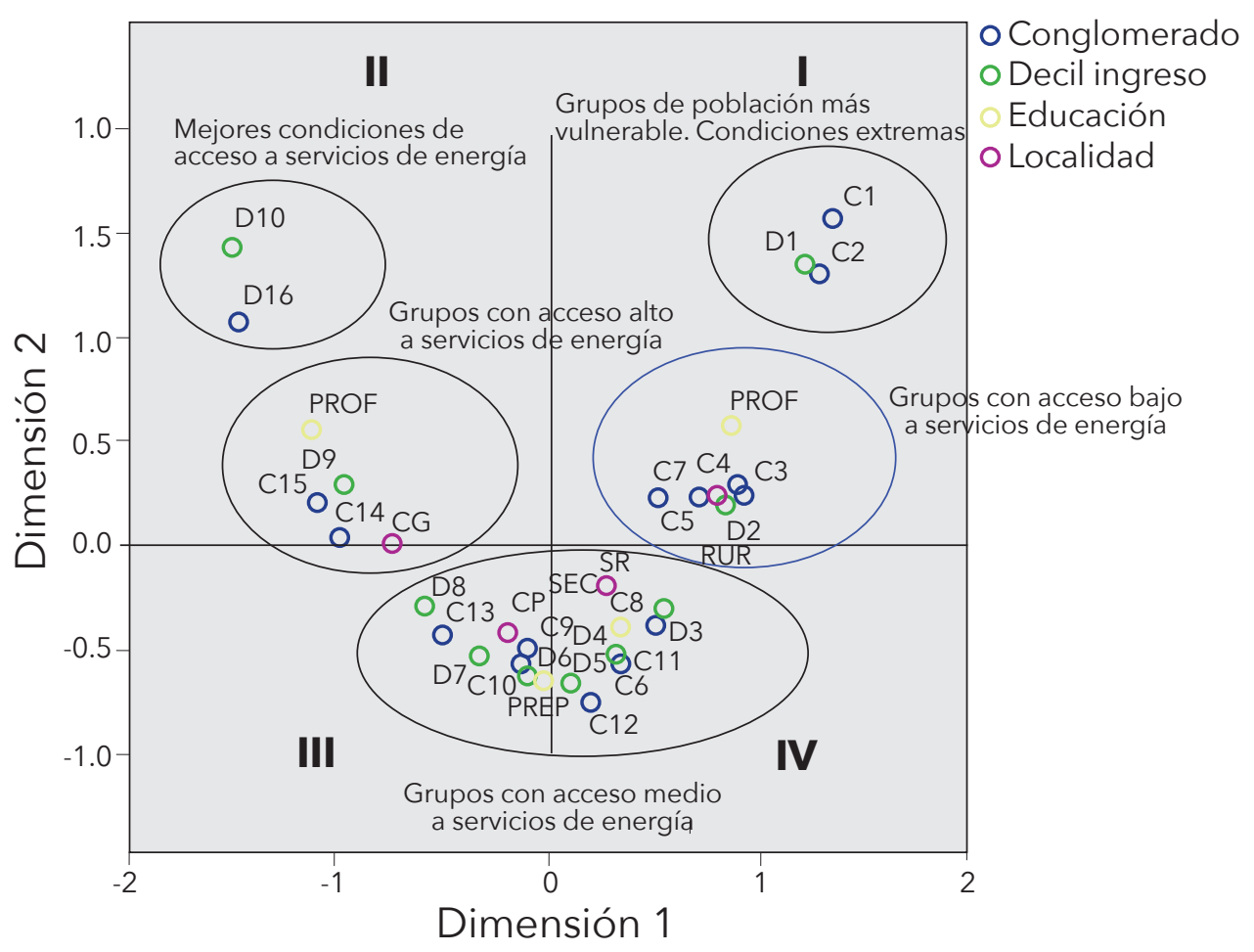

Fuente: elaboración propia. 
puntos forma una figura similar a una parábola o V, de la cual se desprende que las relaciones más significativas entre estas variables se presenten en los valores extremos (primer y segundo cuadrante), relación que pierde fuerza al acercarse al origen del plano factorial, de ahí que los valores medios de las cuatro variables se ubiquen en el tercer y cuarto cuadrante, aunque la relación en este caso es menos clara. Para el objetivo de este trabajo, los resultados más importantes son los del primer cuadrante de la figura 6 ya que, aunque todos los hogares localizados ahí cuentan con electricidad, sufren la privación de la mayoría de los servicios de energía requeridos para satisfacer las necesidades humanas. De esta manera, se comprueba que el hecho de que los hogares mexicanos cuenten con electricidad no significa que tengan acceso a todos los servicios de energía.

\section{Reforzar la meta 7.1 del ODS 7 en la Agenda 2030 de México}

Los resultados y hallazgos obtenidos sustentan la crítica presentada en este trabajo sobre la meta 7.1 del ODS 7 en la Agenda 2030 de México, y representan un insumo empírico que puede ser útil para el análisis de políticas energéticas alternativas, que contribuyan al desarrollo humano y sostenible del país. Los hogares analizados, que representan $99 \%$ del total, cuentan con electricidad, sin embargo, se comprobó que hay un escenario de desigualdad social en este rubro. Es obvio que para mejorar el acceso a servicios de energía limpia y asequible en México es necesario fomentar el desarrollo económico y reducir la desigualdad social y la pobreza. Se reconoce que lograr un cambio sustantivo de la situación económica actual requiere un plazo considerable, pero es posible implementar, desde ahora, políticas y acciones concretas tendientes a mejorarla gradualmente. Para ello, el Estado podría proponer y establecer indicadores adicionales que fortalezcan la meta 7.1 del ODS 7. Es decir, debe considerar que la relación entre energía y desarrollo sostenible trasciende el acceso a energéticos y combustibles, por ello se propone lo siguiente.

1. Diseñar una política energética de desarrollo sostenible y de carácter social que atienda el ODS 7 de la Agenda 2030, y focalizar los esfuerzos en los grupos de población más vulnerable, para establecer compromisos adecuados ya que, de acuerdo con García (2014), García y Graizbord (2016a, 2016b), son los que viven en situación de pobreza energética, como se explicó en los resultados.

2. Implementar una estrategia trasversal que reconozca las interacciones entre energía, desarrollo y medio ambiente. De acuerdo con un estudio realizado en 20 países de América Latina (Kozulj, 2009), las políticas energéticas de la mayoría de dichas naciones, entre ellas México, reconocen, en el discurso, la relación entre energía, pobreza, desarrollo y medio ambiente (en el tema de cambio climático); sin embargo, las políticas de desarrollo implementadas son sectoriales, por lo que no reconocen los vínculos inherentes entre estas 
dimensiones. El tema clave aquí sería confeccionar y poner en marcha políticas de desarrollo sostenibles que enfrenten estos temas de manera integral. Las respuestas a las preguntas de ¿cómo implementar una política energética que mejore el acceso a los servicios de energía en los grupos de población, y reduzca de manera paralela la pobreza?, y ¿cuál es el rol de los servicios de energía limpia y asequible para mejorar el desarrollo humano y proteger al medio ambiente en México?, podrían constituir un insumo de análisis relevante en el diseño y puesta en marcha de políticas de desarrollo sostenible trasversales, las cuales optimizarían el tiempo y los recursos económicos (siempre escasos), así como la gestión administrativa de las instituciones gubernamentales.

3. Contar con servicios de energía limpia y asequible es indispensable para lograr los ODS de la Agenda 2030, por ejemplo, reducir la pobreza de la población (1); erradicar el hambre (2); garantizar una vida sana (3); garantizar una educación incluyente y equitativa (4); lograr la igualdad de género (5); garantizar la disponibilidad y saneamiento de agua (6); promover el crecimiento económico sostenible (8); construir infraestructura resiliente y fomentar la innovación tecnológica (9); lograr ciudades resilientes y sostenibles (11); garantizar modalidades de consumo y producción sostenibles (12); combatir el cambio climático (13); conservar los océanos (14) y usar los ecosistemas terrestres de manera sostenible (15). Ante este escenario, el Estado mexicano debería establecer una estrategia de trasversalidad para alcanzarlos, ya que, en términos de gestión e implementación de políticas públicas, la optimización de los recursos económicos y humanos es siempre un factor fundamental.

Es necesario analizar el papel que desempeña la tecnología para mejorar el acceso a los servicios de energía, y alcanzar un mayor desarrollo sostenible. México tiene alto potencial para el aprovechamiento de energías renovables; no obstante, al revisar los datos de INEGI (2017) se observa que 0.3\% de las viviendas cuenta con paneles fotovoltaicos y 4.9 con calentador solar de agua. Al considerar estos puntos, se deberían integrar las tecnologías limpias y de eficiencia energética, como un elemento primordial para lograr un desarrollo sostenible, tal como lo plantea la Agenda 2030. En esa dirección, los planes y programas de desarrollo (nacionales, subnacionales y sectoriales) han vinculado tradicionalmente a las tecnologías limpias con la dimension ambiental de la sostenibilidad, sobre todo en el tema de cambio climático. Un paso adelante implicaría incluir en ese vínculo la dimensión social de la energía, aunque ya se han dado algunos pasos importantes en ese sentido como el establecimiento, en los últimos 10 años, de programas como el de calentadores solares, la hipoteca verde en viviendas nuevas de interés social y la normalización de los principales enseres electrodomésticos y equipos energéticos como refrigeradores, lámparas y aparatos de aire acondicionado. Sin duda éstos son muy importantes, pero sería pertinente avanzar más, y reconocer que una gran parte de la población, como quedó comprobado en este trabajo, no tiene acceso a los servicios de energía mínimos necesarios para mejorar su bienestar social y desarrollo humano. 


\section{Conclusiones}

La Agenda 2030 para el Desarrollo Sostenible de México reconoce, en el ODS 7 , el papel que desempeñan los servicios de energía para mejorar el bienestar de la población. La meta establecida, sin embargo, refleja una visión reduccionista de la relación entre energía y desarrollo sostenible. El hecho de que un hogar disponga de electricidad no significa que sus integrantes tengan acceso a los servicios de energía mínimos necesarios. Ante esta situación, la política energética y de desarrollo sostenible debería considerar los servicios de energía indispensables en los hogares, para mejorar el bienestar social de la población, aunque no estuvieran en la Agenda 2030.

Con los métodos multivariantes como el análisis de conglomerados de $\mathrm{K}$ medias y el de correspondencias, se probó la hipótesis de que los hogares mexicanos se clasifican en grupos con alta homogeneidad interna y heterogeneidad externa, en función del nivel de acceso a los servicios de energía, escenario que comprueba la diferencia conceptual entre acceso a la energía y a los servicios de energía. Esta realidad reveló un problema de desigualdad social en este campo, el cual se visibilizó al identificar un patrón de relaciones entre los 16 grupos de hogares encontrados y las condiciones económicas, sociales y territoriales. Esta evidencia empírica sustenta la idea de que para que en México los servicios de energía en los hogares contribuyan al desarrollo sostenible, el Estado debe implementar una política energética que reconozca esta diferenciación social, que adopte un enfoque trasversal de sostenibilidad económica, social y ambiental, y que considere la dimensión tecnológica como un elemento sustancial para lograrlo, además de los compromisos adquiridos en la Agenda 2030.

Los resultados obtenidos implican un conocimiento empírico que puede sentar las bases para un abordaje científico interdisciplinario del tema en el futuro. Por ejemplo, la pobreza energética y la desigualdad en los patrones de consumo de energía de la población, la justicia ambiental y la penetración y apropiación de tecnologías renovables en los hogares han cobrado relevancia científica y política en los últimos 10 años en México y América Latina (Kozul, 2009). Dicho abordaje requiere del aporte de economistas, sociólogos, antropólogos, ingenieros, físicos y politólogos para que se responda a preguntas fundamentales como ¿cuáles son las necesidades humanas vinculadas directamente con los servicios de energía?; ¿son absolutas o relativas estas necesidades humanas?; ¿cuáles son los servicios de energía indispensables para satisfacer las necesidades humanas y alcanzar el bienestar de la población?; ¿una transición a energías renovables o de bajas emisiones puede incrementar el tamaño de población con acceso a servicios de energía?, y ¿es factible técnica y económicamente esta transición?

Una política energética y un enfoque científico, con las características comentadas, sentarán las bases para el acceso a energía limpia y asequible, como lo propone la Agenda 2030 para el Desarrollo Sostenible de Naciones Unidas, para que "nadie se quede atrás" (NU, 2018). 


\section{Agradecimientos}

Este trabajo forma parte del proyecto de investigación de ciencia básica "Pobreza energética y cambio climático en la región transfronteriza de México y Estados Unidos", financiado por el Consejo Nacional de Ciencia y Tecnología.

Los autores agradecemos a los revisores anónimos de este artículo por sus comentarios, críticas y sugerencias, ya que contribuyeron significativamente a mejorar su contenido.

\section{Referencias}

Agencia Internacional de Energía-Secretaría de Energía (AIE-SENER). (2011). Indicadores de sustentabilidad energética: 5 sectores, 5 retos. México: SENER. Recuperado de https://www.gob.mx/cms/attachment/file/65305/Bibliograf_a_6.pdf

Baranger, D., y Niño, F. (2009). Introducción al análisis de correspondencias. En D. Baranger (coord.), Construcción y análisis de datos. Introducción al uso de técnicas cuantitativas en la investigación social (pp. 97-121). Buenos Aires: Posadas.

Checkley, W., Epstein, L. D., Gilman, R. H., Figueroa, D., Cama, R. I., Patz, J. A., y Black, R. E. (2000). Effects of El Niño and ambient temperature on hospital admissions for diarrhoeal diseases in Peruvian children. The Lancet, 355(9202), 442-450. doi:10.1016/S0140-6736(00)82010-3

Cravioto, J., y Yamasue, E. (2017). Energy services and life satisfaction: A study on households in two Mexican communities. Trabajo presentado en Energy for Society: 1st International Conference on Energy Research \& Social Science. Sitges, España.

Cravioto, J., Yamasue, E., Okumura, H., e Ishihara, K. N. (2014). Energy service satisfaction in two Mexican communities: A study on demographic, household, equipment and energy related predictors. Energy Policy, (73), 110-126.

Daniels, N. A., MacKinnon, L., Bishop, R., Altekruse, S., Ray, B., Hammond, R. M., Thompson, S., Wilson, S., Bean, N. H., Griffin, P. M., y Slutsker L. (2000). Vibrio parahaemolyticus infections in the United States, 1973-1998. The Journal of Infectious Diseases, 181(5), 1661-1666. doi.org/10.1086/315459

Druckman, A., y Jackson, T. (2008). Household energy consumption in the UK: A highly geographically and socio-economically disaggregated model. Energy Policy, 36(8), 3177-3192.

Evans, G. (2001). Environmental stress and health. En A. Baum, T. Revenson y J. Singer (eds.), Handbook of health psychology (pp. 365-385). Nueva Jersey: Erlbaum.

Everitt, B. S., y Dunn, G. (2001). Applied multivariate data analysis (vol. 2). Londres: Arnold.

Fell, M. J. (2017). Energy services: A conceptual review. Energy Research and Social Science, (27), 129-140. 
García, R. (2014). Pobreza energética en América Latina, (Serie Documentos de proyecto Comisión Económica para América Latina y el Caribe-CEPAL, LC/W.576). Santiago de Chile. CEPAL, Naciones Unidas. Recuperado de http: / / www.cepal.org/cgi-bin/getProd.asp?xml=/publicaciones/xml/8/52578/ P52578. $x m l \& x s l=/$ publicaciones/ficha. $x s$ l\&base=/publicaciones/top publicaciones.xsl

García, R. , y Graizbord, B. (2016a). Caracterización espacial de la pobreza energética en México. Un análisis a escala subnacional. Economía, Sociedad y Territorio, 16(51), 289-337.

García, R., y Graizbord, B. (2016b). Privation of energy services in Mexican households: An alternative measure of energy poverty. Energy Research and Social Science, 18, 36-49.

Gobierno Federal. (2016). México Agenda 2030. Estrategia nacional para la puesta en marcha de la Agenda 2030. Recuperado de https://www.gob.mx/cms/ uploads/attachment/file/412433/Estrategia_Nacional_Implementacion_ Agenda_2030.pdf

Greenacre, M. (2017). Correspondence analysis in practice. Serie Chapman \& Hall/CRC Interdisciplinary Statistics. Boca Ratón: CRC Press.

Hair, J. F., Anderson, R. E., Tatham, R. L., y Black, W. C. (2007). Análisis multivariante. Madrid: Prentice Hall.

Healy, J. D., y Clinch, J. P. (2004). Quantifying the severity of fuel poverty, its relationship with poor housing and reasons for non-investment in energy-saving measures in Ireland. Energy Policy, 32(2), 207-220.

Instituto Nacional de Estadística y Geografía (INEGI). (2017). Encuesta Nacional de Ingresos y Gastos de los Hogares 2016. Recuperado de http://www.beta. inegi.org.mx/proyectos/enchogares/regulares/enigh/nc/2016/default.html

Kaufman, L., y Rousseeuw, P. J. (2009). Finding groups in data: An introduction to cluster analysis (vol. 344). Hoboken: John Wiley \& Sons.

Kozulj, R. (2009). Contribución de los servicios energéticos a los Objetivos de Desarrollo del Milenio y a la mitigación de la pobreza en América Latina y el Caribe. Santiago de Chile: CEPAL, Sociedad Alemana de Cooperación Técnica, Programa de las Naciones Unidas para el Desarrollo.

Küller, R., Ballal, S., Laike, T., Mikellides, B., y Tonello, G. (2006). The impact of light and colour on psychological mood: Across-cultural study of indoor work environments. Ergonomics, 49(14), 1496-1507. doi: 10.1080/00140130600858142 McMichael, A. J., Campbell-Landrum, D. H., Corvalán, C. F., Ebi, K. L., Githeko, A. K., Sheraga, J. D., y Woodward, A. (eds.). (2003). Climate change and human health. Risks and responses. Ginebra: World Health Organization.

Modi, V., McDade, S., Lallement, D., y Saghir, J. (2005). Energy services for the Millennium Development Goals. Washington: The International Bank for Reconstruction and Development/The World Bank/United Nations Development Programme.

Naciones Unidas (NU). (2018). Hacia una nueva agenda de desarrollo sostenible. Recuperado de https://www.un.org/sustainabledevelopment/es/mdgs/ 
O'neill, B. C., y Chen, B. S. (2002). Demographic determinants of household energy use in the United States. Population and Development Review, (28), 53-88.

Practical Action. (2016). Poor people's energy outlook 2016: National energy access planning from the bottom up. Rugby: Practical Action Publishing. doi:10.3362/9781780449357

Resiter, D. B., y Devine Jr., W. D. (1981). Total costs of energy services. Energy, 6(4), 305-315.

Roux, B., de y Rouanet, H. (2010). Multiple correspondence analysis. Quantitative applications in the social sciences. Thousand Oaks: SAGE Publications.

Secretaría de Energía (SENER). (2017). Balance nacional de energía 2016. México: SENER. Recuperado de www.gob.mx/sener/documentos/balance-nacional-de-energia

Sovacool, B. K. (2011). Conceptualizing urban household energy use: Climbing the "energy services ladder". Energy Policy, 39(3), 1659-1668.

Tangkanakul, W., Tharmaphornpilas, P., Datapon, D., y Sutantayawalee, S. (2000). Food poisoning outbreak from contaminated fish-balls. Journal of the Medical Association of Thailand, 83(11), 1289-1295. https: / / europepmc.org/ abstract/med/11215857

Tonello, G. (2008). Seasonal affective disorder: Lighting research and environmental psychology. Lighting Research \& Technology, 40(2), 103-110. doi:10.1177/1477153507083929

United Nations (UN). (2002). Department of Public Information. Plan of Implementation of the World Summit on Sustainable Development. Recuperado de http://www.un.org/esa/sustdev/documents/WSSD_POI_PD/English/WSSD_ Planlmpl.pdf

United Nations (UN). (2009). Department of Public Information. The Millennium Development Goals Report 2009 (includes the 2009 progress chart). Nueva York: United Nations Publications.

Wall, R. , y Crosbie, T. (2009). Potential for reducing electricity demand for lighting in households: An exploratory socio-technical study. Energy Policy, 37(3), 1021-1031. doi.10.1016/j.enpol.2008.10.045

World Health Organization-World Meteorological Organization (WHO-WMO). (2012). Atlas of health and climate. Ginebra: WHO. 